\title{
Perfluoroalkyl and polyfluoroalkyl substances in the lower atmosphere and surface waters of the Chinese Bohai Sea, Yellow Sea, and Yangtze River estuary
}

\author{
Zhen Zhao a,b , Jianhui Tang b,*, Lijie Mi ${ }^{\mathrm{b}}$, Chongguo Tian ${ }^{\mathrm{b}}$, Guangcai Zhong ${ }^{\mathrm{d}}$, Gan Zhang ${ }^{\mathrm{d}}$, Shaorui Wang ${ }^{\mathrm{d}}$, \\ Qilu Li ${ }^{\mathrm{e}}$, Ralf Ebinghaus ${ }^{\mathrm{c}}$, Zhiyong Xie ${ }^{\mathrm{c}}$, Hongwen Sun ${ }^{\mathrm{a}}$ \\ ${ }^{a}$ MOE Key Laboratory of Pollution Processes and Environment Criteria, College of Environmental Science and Engineering, Nankai University, Tianjin 300350, China \\ ${ }^{\mathrm{b}}$ Key Laboratory of Coastal Environmental Processes and Ecological Remediation, Yantai Institute of Coastal Zone Research, Chinese Academy of Sciences, Yantai 264003, China \\ c Helmholtz-Zentrum Geesthacht, Centre for Materials and Coastal Research, Institute of Coastal Research, Max-Planck-Strasse 1, Geesthacht, 21502, Germany \\ ' State Key Laboratory of Organic Geochemistry, Guangzhou Institute of Geochemistry, Chinese Academy of Sciences, Guangzhou, 510640, China \\ e Key Laboratory of Yellow River and Huai River Water Environment and Pollution Control, Ministry of Education, School of Environment, Henan Normal University, Xinxiang 453007, China
}

\section{H I G H L I G H T S}

- PFASs were investigated in the low atmosphere and surface water in northern Chinese seas.

- 8:2 FTOH and PFOA were the predominant compounds in the air and water, respectively.

- Distribution of PFASs were influenced by sources, geographical condition, and ocean currents.

- High levels of PFOA were found in the Laizhou Bay, Bohai Sea.

- Degradation of atmospheric neutral PFASs contributes minimal to ionic PFASs in surface water.

\section{A R T I C L E I N F O}

\section{Article history:}

Received 7 January 2017

Received in revised form 19 April 2017

Accepted 19 April 2017

Available online $\mathrm{xxxx}$

Editor: Jay Gan

Keywords:

PFASs

Air and water

Environmental concentrations

Yellow Sea

PFOA

\footnotetext{
* Corresponding author.

E-mail address: jhtang@yic.ac.cn (J. Tang).
}

GRAPH I C A L A B S T R A C T

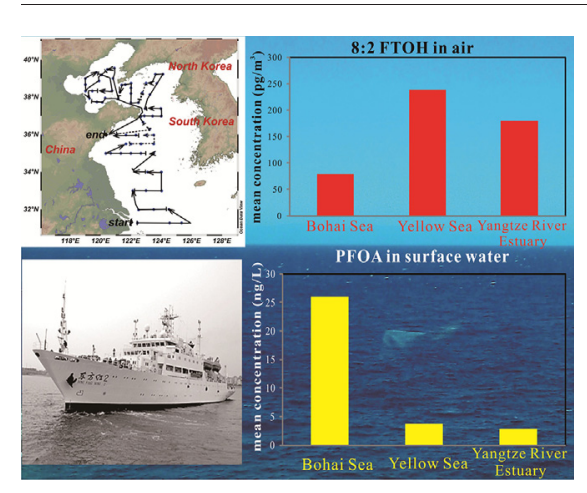

\section{A B S T R A C T}

Polyfluoroalkyl and perfluoroalkyl substances (PFASs), in the forms of neutral polyfluoroalkyl substances in the gas phase of air and ionic perfluoroalkyl substances in the dissolved phase of surface water, were investigated during a sampling campaign in the Bohai Sea, Yellow Sea, and Yangtze River estuary in May 2012. In the gas phase, the concentrations of neutral $\sum$ PFASs were within the range of $76-551 \mathrm{pg} / \mathrm{m}^{3}$. Higher concentrations were observed in the South Yellow Sea. 8:2 fluorotelomer alcohol (FTOH) was the predominant compound as it accounted for $92 \%-95 \%$ of neutral $\sum$ PFASs in all air samples. Air mass backward trajectory analysis indicated that neutral $\sum$ PFASs came mainly from the coast of the Yellow Sea, including the Shandong, Jiangsu, and Zhejiang provinces of China, and the coastal region of South Korea. The fluxes of gas phase dry deposition were simulated for neutral PFASs, and neutral $\sum$ PFASs fluxes varied from 0.37 to $2.3 \mathrm{pg} / \mathrm{m}^{2} / \mathrm{s}$. In the dissolved phase of the surface water, concentrations of ionic $\sum$ PFASs ranged from 1.6 to $118 \mathrm{ng} / \mathrm{L}$, with the Bohai Sea exhibiting higher concentrations than both the Yellow Sea and the Yangtze River estuary. Perfluorooctanoic acid (PFOA) was the predominant compound accounting for $51 \%-90 \%$ of the ionic $\sum$ PFAS concentrations. Releases from industrial and domestic activities as well as the semiclosed geographical conditions increased the level of ionic $\sum$ PFASs in the Bohai Sea. The spatial distributions of perfluoroalkyl carboxylic acids (PFCAs) and perfluoroalkane sulfonic 
acids (PFSAs) were different significantly. The Laizhou Bay was the major source region of PFCAs and the Yangtze River estuary was the major source of PFSAs.

\section{Introduction}

Perfluoroalkyl and polyfluoroalkyl substances (PFASs) have been widely used for $>60$ years because of their lipophobic and hydrophilic characteristics (Kissa, 2001; Lindstrom et al., 2011). PFASs have been found in various environmental compartments worldwide (Houde et al., 2011; Z. Wang et al., 2015; Yamashita et al., 2005). Some longchained PFASs $(C \geq 8)$ are bioaccumulative and toxic, and are thus listed in the national and international regulations (OECD, 2002). After perfluorooctanesulfonic acid (PFOS) and its related compounds were added to the Stockholm Convention's Annex B, their production and use significantly decreased (Lim et al., 2011; UNEP, 2009). Major global manufacturers of perfluorooctanoic acid (PFOA) and its precursors were promised to voluntarily stop their production in 2015 (USEPA, 2006). However, the releases of PFASs continue by other means, for example, the production of irreplaceable homologues, the consumption of stockpiles, and emission from previously-sold commercial products (Kwok et al., 2015; Müller et al., 2011), thereby resulting in high levels in some regions (Heydebreck et al., 2015; Möller et al., 2010; Zhou et al., 2013).

Ionic PFASs are resistant to photolysis, pyrolysis, and biotransformation, thus making them highly persistent in the environment (Kissa, 2001). They have high water solubility because of their carboxylic or sulfonic acid groups, and can be transported across long distances via water (Ahrens, 2011; Yamashita et al., 2005). Open sea water is presumed an important sink of ionic PFAS homologues (Armitage et al., 2009; Yamashita et al., 2005). Neutral PFASs, such as fluorotelomer alcohols (FTOHs), are volatile and are distributed mainly in air rather than in the water phase (Ahrens et al., 2011; Dreyer et al., 2009). Following oxidation by radicals and oxides, neutral PFASs in the air transform to ionic PFASs and then reach the earth's surface through dry/wet deposition, which are considered as indirect sources (Armitage et al., 2009; Butt et al., 2010; Ellis et al., 2004). Compared to the indirect sources, the direct sources are confirmed as the main contributors of PFASs worldwide (Armitage et al., 2009).

Several studies have reported on the PFAS-derived pollutions, especially PFOA and PFOS, along the Chinese coastline (Cai et al., 2012b; So et al., 2004; Wang et al., 2011). The composition of ionic PFASs in surface water was significantly different geographically. In the Pearl River estuary and South China Sea, PFOS was usually observed at higher concentrations as compared to other homologues (Kwok et al., 2015), whereas for the rest of the Chinese coast and seas, PFOA was the predominant pollutant (Wang et al., 2012; T. Wang et al., 2015). The industrial production and use of PFASs resulted in high level detections in some hotspots. For example, the rivers upstream to the Liaodong (Fuxin City) (Bao et al., 2010) and Laizhou (Weifang City) Bays (Heydebreck et al., 2015), of which the direct release of ionic PFASs was suggested as the major source. The previous studies were mostly concentrated in the riverine and coastal region, and little is known in the open sea area.

The Chinese Bohai and Yellow Seas have a combined total area of over $470,000 \mathrm{~km}^{2}$. Hundreds of rivers in China as well as in the Korean Peninsula discharge industrial and domestic wastewater into this region (Jin et al., 2015; Kim, 2012; P. Wang et al., 2014). In the semiclosed Bohai Sea, high concentrations of PFOA and PFOS were detected in the rivers emptying into the sea, which may have elevated the levels of PFOA and PFOS in the seawater (Sun et al., 2011; P. Wang et al., 2014). There are several important industrial provinces, such as Liaoning (where Fuxin City is located), Shandong (where Weifang City is located), Zhejiang, and Jiangsu Provinces along the Bohai Sea and Yellow
Sea coasts. Among the industries present along these coasts, the fluorochemical industries are deemed the most important sources of PFASs. Moreover, rapid economic development along the Bohai and Yellow Sea coasts resulted in a large amount of domestic sewage release to the marine environment (S.W. Xie et al., 2013). Gao et al. (2014) investigated PFASs in marine sediments in the Bohai, Yellow, and East China Seas, and observed a general decreasing trend from the coast to the open sea. Thus far, there has been a lack of studies focusing on PFAS pollution in the air and water covering the Bohai Sea, Yellow Sea, and Yangtze River estuary. Such studies can predict the fates of PFASs in this prominent region.

The present study revealed the pollution characteristics of PFASs in the lower atmospheres and surface waters of the Bohai Sea, Yellow Sea, and Yangtze River estuary. The aims of this study are 1) to characterize the distribution of PFASs in a large scale of Chinese marginal seas; 2 ) to discriminate the importance of direct (riverine discharge) and indirect sources (atmospheric degradation) on the PFASs in the open seas. The large geographical scale of this study was beneficial in comprehensively elaborating the sources and transport processes of such pollutants.

\section{Material and methods}

\subsection{Standards and reagents}

Twenty-nine neutral and ionic PFASs were analyzed, specifically 6:2, 8:2, 10:2, and 12:2 FTOHs; 6:2 and 8:2 fluorotelomer acrylates (FTACs); $N$-methyl perfluorobutane sulfonamide (MeFBSA); $N$-methyl perfluorooctane sulfonamide (MeFOSA); N-ethyl perfluorooctane sulfonamide (EtFOSA); $\mathrm{N}$-methyl perfluorobutane sulfonamidoethanol (MeFBSE); $\mathrm{N}$-methyl perfluorooctane sulfonamidoethanol (MeFOSE); and $N$-ethyl perfluorooctane sulfonamidoethanol (EtFOSE) were measured in the air samples and $C_{4}-C_{6}, C_{8}$, and $C_{10}$ perfluoroalkane sulfonic acids (PFSAs); $\mathrm{C}_{4}-\mathrm{C}_{14}$ perfluoroalkyl carboxylic acids (PFCAs); and perfluorooctanesulfonamide (FOSA) were measured in the surface water samples.

Sixteen mass-labeled analytes were used as the Internal Standards (IS) including ${ }^{2} \mathrm{H}$-labeled perfluoroalkane sulfonamides (FASAs), perfluoroalkane sulfonamidoethanols (FASEs), and ${ }^{13} \mathrm{C}$-labeled FTOHs for the air samples (IS I) and ${ }^{13} \mathrm{C}$-labeled ionic PFCAs and FOSAs and ${ }^{18}$ O-labeled perfluorohexanesulfonate (PFHxS) for the water samples (IS II) (Table S1). For the air samples, 9:1 FTOH was employed as the injection standard (InjS) I and 2H-perfluoro-[1,2- $\left.{ }^{13} \mathrm{C}_{2}\right]$-2-decenoic acid (8:2 FTUCA) was employed as the InjS II for the water samples. FTACs and 9:1 FTOH were purchased from Fluorochemo Ltd. (Derbyshire, United Kingdom). The other standards were purchased from Wellington Laboratory Inc. (Ontario, Canada). Table S1 lists the information about the target compounds and standards in detail. Methanol, acetone, dichloromethane (DCM), and $n$-hexane were all residue grade and purchased from Merck (Darmstadt, Germany). Ammonium hydroxide $\left(\mathrm{NH}_{4} \mathrm{OH}\right)(25 \%)$ was also purchased from Merck (Darmstadt, Germany). Ultrapure Millipore water was produced by a Milli-Q® Plus 185 system (Zug, Germany).

\subsection{Sample collection}

Air and surface water samples were collected from May 2-20, 2012 from the research vessel Dongfanghong-2. The sampling area covered the Bohai Sea, Yellow Sea, and the Yangtze River estuary in China (Fig. 
S1). Information about the sampling stations is summarized in Tables S2 and S3.

Fifteen air samples were taken using a high-volume air sampler, which was placed in the front of the ship's upper deck. Each sample was collected as a 24-hour nonstop air mass with a mean flow rate of $18 \pm 3.2 \mathrm{~m}^{3} / \mathrm{h}$ and a mean volume of $429 \pm 79 \mathrm{~m}^{3}$. Detailed information can be found elsewhere (Z. Wang et al., 2014; Z. Xie et al., 2013). Briefly, a glass fiber filter (GFF, $12 \mathrm{~cm}$ diameter, $0.7 \mu \mathrm{m}$ pore size) trapped airborne particles and a self-packed polyurethane (PUF)/XAD-2 glass column (PUF: $\Phi 5.0$ and 2.5 cm length; 35 g XAD-2, particle size: $0.3-$ $1.0 \mathrm{~mm}$ ) trapped the gaseous phase. Two cartridges were used in series for samples A1, A8, and A16 to monitor the breakthrough of the PFASs in the cartridges. Before sampling, the filters were baked at $450{ }^{\circ} \mathrm{C}$ for $12 \mathrm{~h}$ and the columns were Soxhlet extracted for $16 \mathrm{~h}$ with acetone to remove any contaminants. After sampling, the filters and columns were stored at $-20^{\circ} \mathrm{C}$ until further treatment in a clean lab. Three procedural blanks of air samples were prepared.

Using a stainless steel basket, 72 surface water samples (depth: 0 $30 \mathrm{~cm}$ ) were collected from 67 sampling sites, including 5 duplicated samples at site W9, W14, W27 and W50 (two duplicated samples at W50), and stored in 1-L polypropylene (PP) bottles which were cleaned by methanol and rinsed by samples prior to their usage. Details on the water sampling procedures can be found elsewhere (Cai et al., 2012c). Briefly, a glass fiber filter (GFF, Ø47 mm, pore size: $1.2 \mu \mathrm{m}$ ) was used for filtration. The dissolved phase was first spiked by $1 \mathrm{ng}(50 \mathrm{pg} / \mu \mathrm{L}$, $20 \mu \mathrm{L}$ ) IS II and then solid-phase-extracted (SPE) onboard using Oasis WAX cartridges (Waters, $150 \mathrm{mg}, 6 \mathrm{~cm}^{3}, 30 \mu \mathrm{m}$ ) at a speed of 2 drops per second via gravity. Three breakthrough cartridges were conducted at stations W1, W30 and W67. The filters were baked at $450{ }^{\circ} \mathrm{C}$ for $4 \mathrm{~h}$ before use, and the cartridges were preconditioned with $10 \mathrm{~mL}$ of methanol prior to water loading. The sample-loaded filters and cartridges were stored at $-20{ }^{\circ} \mathrm{C}$ before further treatment in a clean lab. Six field blank and eight laboratory blank samples were prepared for the water analysis.

\subsection{Extraction}

Sample extractions were performed in a clean lab (Class 10000) with Teflon-free materials. The air columns were Soxhlet extracted by DCM for $16 \mathrm{~h}$ after being spiked with $2.5 \mathrm{ng}(50 \mathrm{pg} / \mu \mathrm{L}, 50 \mu \mathrm{L})$ IS I. The extracts were rotary evaporated to 1 to $2 \mathrm{~mL}$ using $n$-hexane as the keeper. Following the removal of the residual water by passing the extract through $3 \mathrm{~g}$ of prebaked $\mathrm{Na}_{2} \mathrm{SO}_{4}$, the extracts were concentrated down to $150 \mu \mathrm{L}$ under a gentle nitrogen flow (>99.999\%). Prior to the instrumental analysis, the concentrated extracts were spiked with $1 \mathrm{ng}$ $(50 \mathrm{pg} / \mu \mathrm{L}, 20 \mu \mathrm{L}$ ) InjS I. Neutral PFASs, for instance, 8:2 FTOH had a low affinity to particles, and exhibited a partitioning coefficient varying between $1 \%$ and $3 \%$. The air filters were not analyzed in this study (Ahrens et al., 2011; Cai et al., 2012a; Labadie and Chevreuil, 2011; Zhou et al., 2013). The WAX cartridges were first washed with $15 \mathrm{~mL}$ Millipore water to remove the salt, and then dried using a vacuum pump. The cartridges were eluted using $10 \mathrm{~mL}$ methanol with $0.1 \%$ $\mathrm{NH}_{4} \mathrm{OH}$. The eluents were concentrated down to $150 \mu \mathrm{L}$. The eluents were spiked with $1 \mathrm{ng}(50 \mathrm{pg} / \mu \mathrm{L}, 20 \mu \mathrm{L})$ InjS II before instrumental analysis. The suspended particles were not analyzed in this study (Labadie and Chevreuil, 2011; Zhou et al., 2013). InjS I and II were used to calculate the recoveries and to supervise the performance of the instruments.

\subsection{Instrumental analysis}

For the neutral PFASs in the air samples, quantification was performed by gas chromatography (6890, Agilent Technologies, Waldbronn, Germany)/mass spectrometry (Agilent Technologies) (GC/MS) with a positive chemical ionization (PCI) in the selected ionmonitoring (SIM) mode. For the ionic PFASs in the water samples, quantification was performed using a high performance liquid chromatography-negative electrospray ionization-tandem mass spectrometry system (HPLC- $(-)$ ESI-MS/MS) that consisted of an HP 1100 HPLC system (Agilent Technologies) coupled to an API 3000 triplequadrupole mass spectrometer (Applied Biosystems/MDS SCIEX). The characteristic ions for GC/MS and precursor/product ions for HPLCMS/MS are listed in Table S1. The range of the calibration curve for $\mathrm{GC} / \mathrm{MS}$ was $0,5.0,12.5,25,50,125$, and $250 \mathrm{pg} / \mu \mathrm{L}$. The main calibration range was $0,0.5 .1 .0,5.0,10$, and $20 \mathrm{pg} / \mu \mathrm{L}$ for HPLC-MS/MS. In some samples, where the concentrations were out of the curve, the range changed to $0,10,20,50,100$, and $200 \mathrm{pg} / \mu \mathrm{L}$. More details on the instrumental analyses can be found elsewhere (Ahrens et al., 2009).

\subsection{Quality assurance and quality control}

The instrumental detection limit (IDL) was defined using a signal-tonoise ratio of 3 . The method quantification limit (MQL) was determined using a signal-to-noise ratio of 10 for the analytes not detected in the blank samples. For the analytes detected in the blank samples, the MQLs were extrapolated under $98 \%$ confidence intervals of the concentrations in the blank samples and their standard deviations. No compounds were found in air blank samples. Only PFOA was found in the blank water samples, which had an average concentration of $33 \mathrm{pg} / \mathrm{L}$ and a standard variation of $9.6 \mathrm{pg} / \mathrm{L}$. The IDLs and MQLs for the individual compounds are presented in Table S4. For the air samples, breakthrough columns were connected and analyzed separately as real samples. No compounds were found in the breakthrough samples. For the water samples, the breakthroughs of the cartridges were also tested, and no cartridge was found to be overloaded. PFAS concentrations in the duplicated samples exhibited a deviation within $\pm 25 \%$. The performances of the instruments were stable throughout the entire injection procedures. Recoveries for the individual ISs are listed in Table S5. The average recoveries ranged from $38 \% \pm 10 \%$ for ${ }^{13} \mathrm{C}_{8}$-FOSA to $119 \% \pm$ $36 \%$ for ${ }^{13} \mathrm{C}_{4}$-PFBA. The concentrations were all corrected by the corresponding recoveries.

\subsection{Air mass backward trajectories}

Using NOAA's HYSPLIT model (with $50 \mathrm{~m}$ as the arrival height (http://www.arl.noaa.gov/HYSPLIT_info.php)), a 120-h backward trajectory analysis for the air masses was modeled. The air mass backward trajectories for individual air samples are presented in Fig. S2.

\subsection{Gas phase dry deposition velocity}

The dry deposition velocity (vd) was estimated by a series of resistances to vertical transfer and surface uptake (Ma et al., 2003; Ma and Daggupaty, 2000) as follows:

$v_{d}=\frac{1}{R_{a}+R_{b}+R_{s}}$

$R_{a}, R_{b}$, and $R_{s}$ represent the bulk aerodynamic, quasi-laminar sublayer, and surface resistances, respectively. The aerodynamic resistance was estimated as follows:

$$
R_{a}=\frac{\ln \left(\frac{z}{z_{0}}\right)-\psi_{c}\left(\frac{z}{L_{i}}\right)}{\kappa\left\langle u_{*}^{2}\right\rangle^{1 / 2}}
$$

$\psi_{c}=\int_{Z_{0} / L}^{z / L}\left[1-\varphi_{c}(x)\right] d x / x$

where $z_{0}$ and $L$ are the roughness length and Monin-Obukhov length, respectively. The non-dimensional concentration gradient is presented 
as follows:

$$
\begin{aligned}
& \varphi_{c}\left(\frac{z}{L}\right)=\left(1-14 \frac{z}{L}\right)^{-1 / 2} \text { for } \mathrm{z} / \mathrm{L}<0 \\
& \varphi_{c}=1+8 \frac{z}{L} \text { for } \mathrm{z} / \mathrm{L}>0 \\
& \left\langle u_{*}^{2}\right\rangle^{1 / 2}=\frac{\kappa u L}{\ln \left(\frac{L}{z_{0}}\right)-\psi_{m}}
\end{aligned}
$$

$\psi_{m}=\int_{\frac{z_{0}}{L}}^{z}\left[1-\varphi_{m}(x)\right] d x / x$

$\varphi_{m}\left(\frac{Z}{L}\right)=\left(1-16 \frac{Z}{L}\right)^{-1 / 4}$ for $\mathrm{z} / \mathrm{L}<0$

$\varphi_{m}=1+5.3 \frac{z}{L}$ for $\mathrm{z} / \mathrm{L}>0$

The effective $R_{b}$ is defined as follows:

$\mathrm{R}_{\mathrm{b}}=\frac{2}{\kappa\left\langle u_{*}^{2}\right\rangle^{1 / 2}}\left(\frac{\mathrm{Sc}}{\mathrm{Pr}}\right)^{2 / 3}$

where $\operatorname{Pr}$ is the turbulent Prandtl number $(\operatorname{Pr}=0.71)$, and $\mathrm{Sc}$ is the Schmidt number $(\mathrm{Sc}=3000)$.

The surface resistance (Rs) depends primarily on the nature of the surface and the characteristics of the depositing gas. Rs was estimated by the two-film model as follows:

$\frac{1}{R s}=\frac{R T}{H} \times \frac{1}{k a}+\frac{1}{k w}$

where $\mathrm{R}$ is the gas constant $\left(8.3 \mathrm{~Pa} \mathrm{~m}^{3} / \mathrm{mol} / \mathrm{K}\right), \mathrm{T}(\mathrm{K})$ is the absolute temperature, and $\mathrm{H}\left(\mathrm{Pa} \mathrm{m}^{3} / \mathrm{mol}\right)$ is the Henry's law constant. $\mathrm{k}_{\mathrm{w}}$ and $\mathrm{k}_{\mathrm{a}}$ are water-side and air-side mass transfer coefficients, respectively, and are defined as follows:

$$
\begin{aligned}
& k_{a}=10^{-3}+46.2 \times 10^{-3} U^{*} \operatorname{Sc}(a)^{-0.67} \\
& \mathrm{k}_{\mathrm{w}}=10^{-6}+144 \times 10^{-4}\left(\mathrm{U}^{*}\right)^{22} \mathrm{Sc}(\mathrm{w})^{-0.5} \mathrm{U}^{*}<0.3 \mathrm{~m} / \mathrm{s} \\
& \mathrm{k}_{\mathrm{w}}=10^{-6}+34.1 \times 10^{-4} \mathrm{U}^{*} \mathrm{Sc}(\mathrm{w})^{-0.5} \mathrm{U}^{*}>0.3 \mathrm{~m} / \mathrm{s} \\
& \mathrm{U}^{*}=\left[\left(0.61+0.063 \mathrm{U}_{10} \times 10^{-3}\right]^{0.5} \mathrm{U}_{10}\right.
\end{aligned}
$$

where $\mathrm{Sc}(\mathrm{a})$ and $\mathrm{Sc}(\mathrm{w})$ are the air (2.9) and water (1000) phase Schmidt numbers, respectively, and $U_{10}$ is the wind speed at $10 \mathrm{~m}$ height.

\section{Results and discussion}

\subsection{PFASs in air and surface water}

\subsubsection{Neutral PFASs in air}

In the gas phase, 10 neutral PFASs were detected, i.e., 6:2, 8:2, 10:2, and 12:2 FTOH; 8:2 FTAC; MeFOSA; EtFOSA; MeFBSA; EtFOSE; and MeFBSE. The concentrations of the individual PFASs and neutral $\sum$ PFASs are presented in Table S6 and the statistics of concentrations are presented in Table 1 . The $\sum$ PFAS concentrations ranged from 76 to $551 \mathrm{pg} / \mathrm{m}^{3}$. The $\sum$ FTOH concentrations (73 to $540 \mathrm{pg} / \mathrm{m}^{3}$ ) were one to three orders of magnitude higher than the $\sum$ FTACs $(<0.20$ to

\begin{tabular}{|c|c|c|c|c|c|}
\hline Compound & Max & Min & Mean & Median & SD \\
\hline 6:2 FTOH & 6.7 & 0.83 & 2.9 & 2.3 & 1.9 \\
\hline 8:2 FTOH & 429 & 55 & 182 & 154 & 109 \\
\hline 10:2 FTOH & 85 & 13 & 34 & 25 & 22 \\
\hline 12:2 FTOH & 22 & 1.1 & 5.5 & 3.6 & 5.3 \\
\hline ¿FTOHs & 543 & 73 & 224 & 188 & 134 \\
\hline $8: 2$ FTAC & 1.4 & $<0.20$ & 0.58 & 0.46 & 0.39 \\
\hline ¿FTACs & 1.4 & $<0.20$ & 0.58 & 0.46 & 0.39 \\
\hline MeFOSA & 1.0 & $<0.1$ & 0.43 & 0.32 & 0.33 \\
\hline EtFOSA & 8.5 & 0.49 & 3.0 & 2.3 & 2.3 \\
\hline MeFBSA & 1.9 & 0.63 & 1.0 & 0.86 & 0.43 \\
\hline$\Sigma$ FASAs & 11 & 1.3 & 4.4 & 3.8 & 2.6 \\
\hline EtFOSE & 0.27 & $<0.10$ & 0.18 & 0.17 & 0.05 \\
\hline MeFBSE & 1.5 & 0.14 & 0.50 & 0.31 & 0.38 \\
\hline$\Sigma$ FASEs & 1.5 & 0.14 & 0.61 & 0.49 & 0.39 \\
\hline$\Sigma$ PFASs & 551 & 76 & 229 & 193 & 136 \\
\hline
\end{tabular}
$\left.1.4 \mathrm{pg} / \mathrm{m}^{3}\right), \sum$ FASAs ( 1.3 to $\left.11 \mathrm{pg} / \mathrm{m}^{3}\right)$, and $\sum$ FASEs $(0.14$ to $1.5 \mathrm{pg} / \mathrm{m}^{3}$ ). The predominant compound was $8: 2 \mathrm{FTOH}$, given that it exhibited concentrations ranging from 55 to $430 \mathrm{pg} / \mathrm{m}^{3}$, which accounted for $92 \%$ to $99 \%$ of the $\sum$ PFASs. The concentrations of the other FTOH
Table 1

Statistics of the neutral PFAS concentrations in air $\left(\mathrm{pg} / \mathrm{m}^{3}\right)$.

homologues declined in the following order: 10:2 FTOH $>12: 2$ FTOH $>6: 2 \mathrm{FTOH}$, which were consistent with those in the atmosphere above the Japan Sea and Bering Sea (Cai et al., 2012a). The ratios of the $6: 2$ to $8: 2$ and $10: 2$ to $8: 2$ FTOHs ranged from 0.01 to 0.04 and 0.08 to 0.33 , respectively. The $6: 2$ to $8: 2$ FTOH ratios were similar to the fluorotelomer-based polymers which comprise about $80 \%$ of linear fluorotelomer product (6:2 to 8:2 FTOH ratio: 0.02 ), and this suggest that the source is from the fluorotelomer industry. However, the 10:2 to $8: 2 \mathrm{FTOH}$ ratios were lower than the products (10:2 to $8: 2 \mathrm{FTOH}$ ratio: 0.6) (Li et al., 2011; Washington et al., 2014). One possible reason for the lower 10:2 to 8:2 FTOH ratio may be the higher 10:2 FTOH removal rate as compared to that of 8:2 FTOH in air given that the residence time of 10:2 FTOH (70 days) was shorter than 8:2 FTOH (80 days) (Lai et al., 2016). Another possible reason may be the higher affinity to particles due to the longer of $10: 2 \mathrm{FTOH}$ chain than that of $8: 2$ FTOH (Z. Wang et al., 2014). The mean concentration of the $\sum$ FASAs was $4.4 \pm 2.6 \mathrm{pg} / \mathrm{m}^{3}$, which was significantly higher than that of the $\sum$ FASEs (mean $0.61 \pm 0.39 \mathrm{pg} / \mathrm{m}^{3}$ ). FASAs last longer in air than FASEs and have the potential to be transported across longer distances than FASEs (D'Eon et al., 2006). MeFBSA and MeFBSE were detected in all samples, and showed higher concentrations than those of MeFOSA and Me/EtFOSE, which may be attributed to the replacement of $\mathrm{C}_{8}$-PFASs (Lai et al., 2016). In the air samples from the Bohai and Yellow Seas, only 8:2 FTAC was detected at low levels $\left(<0.20-1.4 \mathrm{pg} / \mathrm{m}^{3}\right)$ in the gas phase. FTACs have a relatively shorter lifetime (about 1 day) than FTOHs (about 20 days) in the atmosphere and may not be transported over long ranges (Butt et al., 2009).

\subsubsection{Ionic PFASs in surface water}

In the water dissolved phase, 10 PFASs were detected, specifically $\mathrm{C}_{4}-\mathrm{C}_{10}$ PFCAs and $\mathrm{C}_{4}, \mathrm{C}_{6}$, and $\mathrm{C}_{8}$ PFSAs, with detection frequencies ranging from 3 to $100 \%$. The individual and ionic $\sum$ PFASs concentrations are shown in Table S7. The statistics of the ionic PFAS concentrations are presented in Table 2. In the Bohai Sea, the $\sum$ PFAS concentrations ranged from 3.9 to $118 \mathrm{ng} / \mathrm{L}$ (mean: $31 \pm 35 \mathrm{ng} / \mathrm{L}$, median: $15 \mathrm{ng} / \mathrm{L}$ ). In the Yellow Sea and Yangtze River estuary, significantly lower $\sum$ PFAS concentrations were observed than in the Bohai Sea, with concentrations ranged from 1.6 to $17 \mathrm{ng} / \mathrm{L}$ (mean: $5.4 \pm 4.2 \mathrm{ng} / \mathrm{L}$, median: $3.9 \mathrm{ng} / \mathrm{L}$ ) in the Yellow Sea and from 1.7 to $12 \mathrm{ng} / \mathrm{L}$ (mean $4.9 \pm$ $3.9 \mathrm{ng} / \mathrm{L}$, median $3.3 \mathrm{ng} / \mathrm{L}$ ) in the Yangtze River estuary. The two highest concentrations of $108 \mathrm{ng} / \mathrm{L}$ and $118 \mathrm{ng} / \mathrm{L}$ were detected at sites W65 and W66, respectively, in the Laizhou Bay, Bohai Sea, where industrial discharge from adjacent rivers may be the major sources (P. Wang et al., 2014).

The $\sum$ PFCA concentrations ( 1.4 to $117 \mathrm{ng} / \mathrm{L}$ ) were dramatically higher than the $\sum$ PFSAs ( 0.1 to $1.3 \mathrm{ng} / \mathrm{L}$ ) in the studied region. PFOA was the predominant compound and accounted for $51 \%$ to $90 \%$ of the 


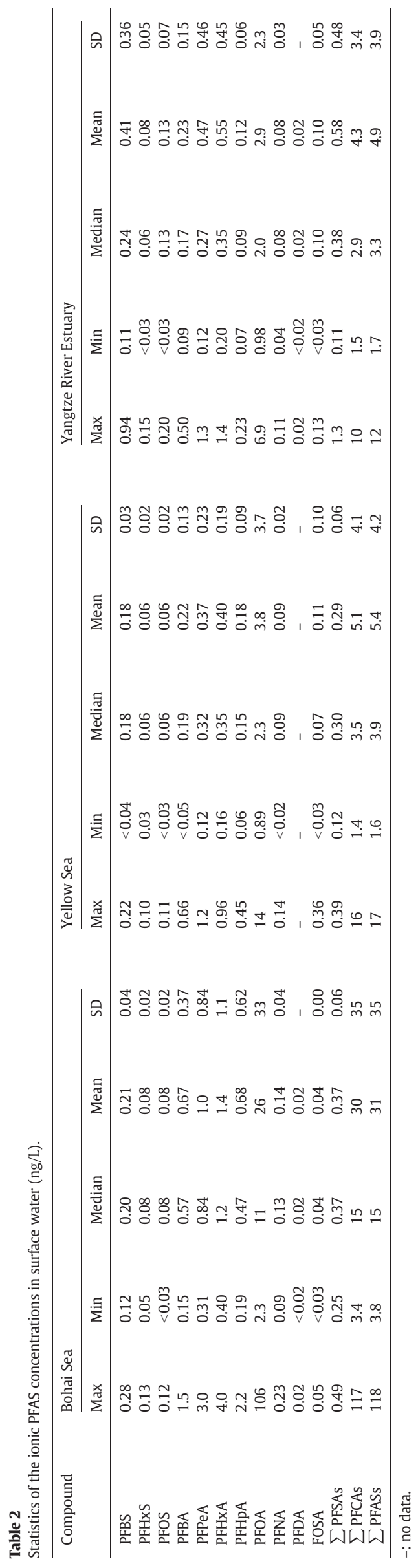

$\sum$ PFAS concentrations. Higher PFOA concentrations were observed in the Bohai Sea (mean: $26 \pm 33 \mathrm{ng} / \mathrm{L}$ ) than in the Yellow Sea (mean: $3.8 \pm 3.7 \mathrm{ng} / \mathrm{L}$ ) and the Yangtze River estuary (mean: $2.9 \pm 2.3 \mathrm{ng} / \mathrm{L}$ ) and it is mainly due to the large inputs from the Laizhou Bay coast (Heydebreck et al., 2015) and the weak water exchange capacity of the Bohai Sea. The percentage of PFBA to $\sum$ PFAS concentration varied from $1 \%$ to $10 \%$ and the PFBA concentrations in the Bohai Sea (mean: $0.67 \pm 0.37 \mathrm{ng} / \mathrm{L}$ ) were higher than in the Yellow Sea (mean: $0.22 \pm$ $0.13 \mathrm{ng} / \mathrm{L}$ ) and Yangtze River estuary (mean: $0.23 \pm 0.15 \mathrm{ng} / \mathrm{L}) . \mathrm{In}$ China, relatively high concentrations of PFBA (up to $6280 \mathrm{ng} / \mathrm{L}$ ) have been reported in an inland aquatic system (Tangxun Lake) which receiving industrial wastewater and WWTP effluents (Zhou et al., 2013). However, the concentration of PFBA in the current study was relatively low (mean of $0.23 \pm 0.15 \mathrm{ng} / \mathrm{L}$ ) partly due to its open water conditions as compared to the closed Tangxun Lake. Another substitute, PFHxA, exhibited concentrations ranging from 0.2 to $4.1 \mathrm{ng} / \mathrm{L}$ (Bohai Sea: $1.4 \pm$ $1.1 \mathrm{ng} / \mathrm{L}$, Yellow Sea: $0.40 \pm 0.19 \mathrm{ng} / \mathrm{L}$, and Yangtze River estuary: $0.55 \pm 0.45 \mathrm{ng} / \mathrm{L}$ ) with a proportion of the $\sum$ PFAS concentration ranging from $3 \%$ to $12 \%$. The alternative homologues (PFBA: $<0.05$ to $1.5 \mathrm{ng} / \mathrm{L}$ and PFHxA: 0.16 to $4.1 \mathrm{ng} / \mathrm{L}$ ) did not exhibit comparable or significantly higher levels than the legacy one (PFOA), thereby indicating that the C8 pollution was the major problem in the coastal region of North China until 2012. Other PFCA homologues minimally contributed to the $\sum$ PFCA concentrations. PFPeA (perfluoropentanoic acid) and PFHpA exhibited average compositions of $7 \%$ and $4 \%$, respectively. Longerchained PFCAs $(C>8)$ were not detected in most of the surface water samples. Gao et al. (2008) reported a high detection frequency for PFDA and PFUnDA in sediment and attributed the degradation of precursors as the cause. In the surface waters, PFDA and PFUnDA concentrations were below the detection limit $(0.02 \mathrm{ng} / \mathrm{L})$. Given that longerchained PFASs have a higher affinity for organic matter and particles, they may be transported by suspended matter from the sea surface to the sediment.

PFOS accounted for $4 \%$ of the $\sum$ PFAS concentrations, which was significantly lower than that of PFOA. The concentrations ranged from $<0.03$ to $0.12 \mathrm{ng} / \mathrm{L}$ (mean: $0.08 \pm 0.02 \mathrm{ng} / \mathrm{L}$ ) in the Bohai Sea, $<0.03$ to $0.11 \mathrm{ng} / \mathrm{L}$ (mean: $0.06 \pm 0.02 \mathrm{ng} / \mathrm{L}$ ) in the Yellow Sea, and $<0.03$ to $0.20 \mathrm{ng} / \mathrm{L}$ (mean: $0.13 \pm 0.07 \mathrm{ng} / \mathrm{L}$ ) in the Yangtze River estuary. Similar composition patterns for PFOA and PFOS were reported in the Bohai Bay (S. Wang et al., 2015) and in the south Bohai coastal rivers (P. Wang et al., 2014). PFBS, which was a substitute of PFOS, occurred at concentrations from <0.04 to $0.9 \mathrm{ng} / \mathrm{L}$ (Möller et al., 2010; Zhou et al., 2013). FOSA, a neutral PFAS, was detected in $36 \%$ of the water samples with concentrations ranging from $<0.03$ to $0.36 \mathrm{ng} / \mathrm{L}$ (mean: $0.10 \pm 0.09 \mathrm{ng} / \mathrm{L}$ ). FOSA is an intermediate of the (bio)transformation of Et-FOSA(E) to PFOS, thereby suggesting the presence of (bio)degradation in the coastal water (Nguyen et al., 2013; Plumlee et al., 2009; Schenker et al., 2008).

\subsection{Distributions, sources, and gas phase dry deposition of neutral PFASs}

The spatial distribution of neutral PFASs in marine boundary air is presented in Fig. 1 and the air mass backward trajectories for each air sample are shown in Fig. S2. Samples collected in the South Yellow Sea (A1-A6) had higher $\sum$ PFAS concentrations (76 to $511 \mathrm{pg} / \mathrm{m}^{3}$, mean: $302 \mathrm{pg} / \mathrm{m}^{3}$ ) than those from the North Yellow and Bohai Seas (A8-A14) (85 to $223 \mathrm{pg} / \mathrm{m}^{3}, 146 \mathrm{pg} / \mathrm{m}^{3}$ ). Previous studies reported high neutral PFAS concentrations in air along the coastal cities of the South Yellow Sea. For instance, Li et al. (2011) reported neutral $\sum$ PFAS concentrations between 113 and $306 \mathrm{pg} / \mathrm{m}^{3}$ in the Yellow Sea coastal cities of China, and Kim et al. (2012) reported mean concentration of $\sum$ FTOHs and $\sum$ FASEs + FASAs of 19,731 and $260 \mathrm{pg} / \mathrm{m}^{3}$, respectively, in the outdoor Korean air. Air masses from the Korea Peninsula coast and the Japan Sea (A9-A11) exhibited lower $\sum$ PFAS concentrations ( 170 to $220 \mathrm{pg} / \mathrm{m}^{3}$ ) than those from the south Yellow Sea (A1-A8, 192 to $511 \mathrm{pg} / \mathrm{m}^{3}$ ). Cai et al. (2012a) reported a neutral gas phase $\sum$ PFAS concentration of $346 \mathrm{pg} / \mathrm{m}^{3}$ in the Japan Sea, and 


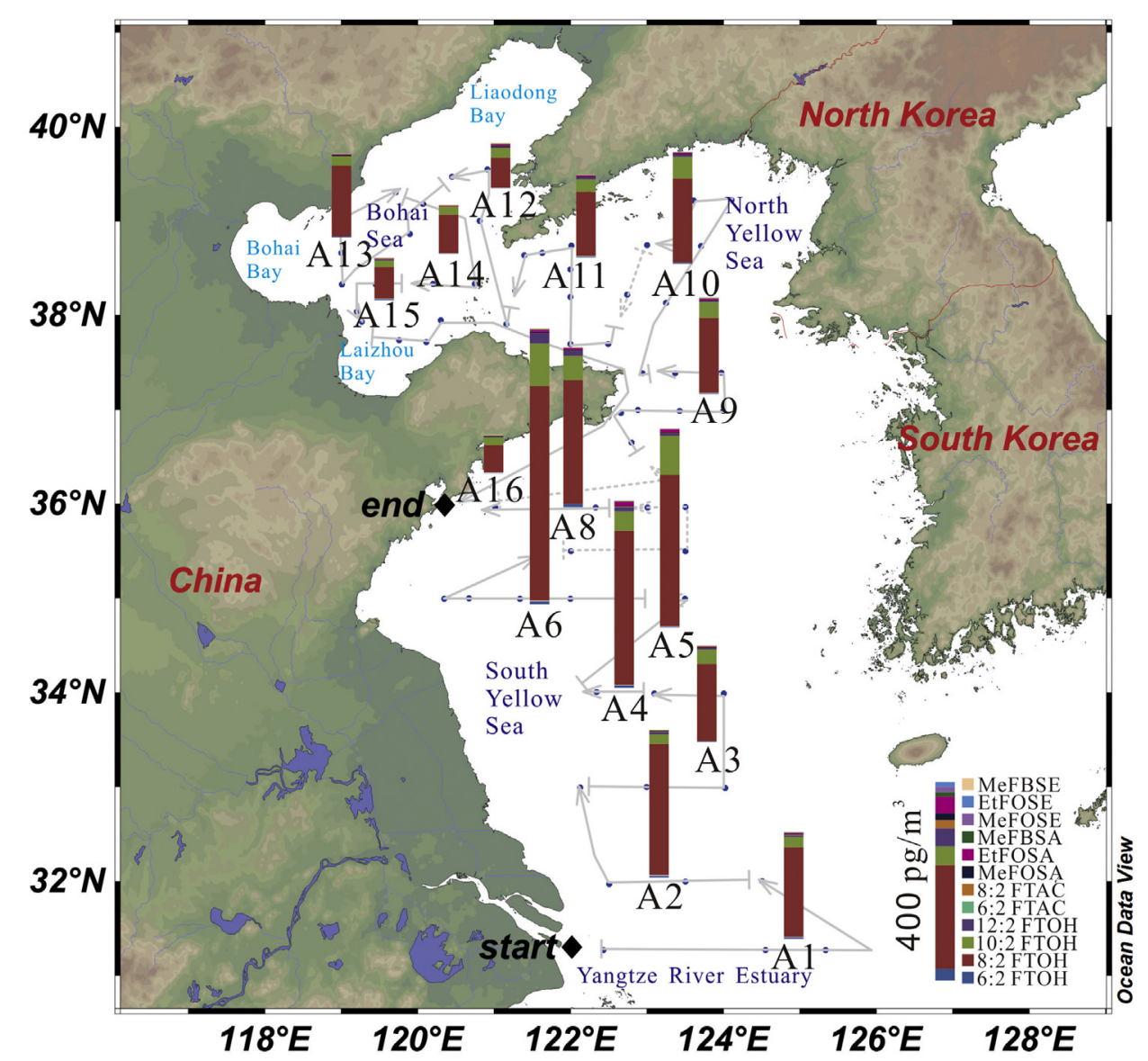

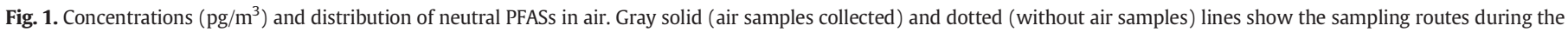
cruises from the start (Shanghai) to the end (Qingdao).

the PFASs pollution from the Japan Sea could transport to the Yellow Sea. The air mass from Mongolia and Russia (A12-A16) exhibited lower $\sum$ PFAS concentrations ( 85 to $98 \mathrm{pg} / \mathrm{m}^{3}$ ) than from the Asian background sites ( 110 to $140 \mathrm{pg} / \mathrm{m}^{3}$ ) (Li et al., 2011).

The results of the Pearson relationship tests are listed in Table S8. The concentrations of the FTOH homologues exhibited significant relevance ( $p<0.05$ ), thereby indicating similar sources. MeFBSA was highly correlated with FTOHs, thereby suggesting the application of $\mathrm{C}_{4}$ precursors. Interestingly, FOSE/As were not related to each other as much as the other PFASs were. The global regulation of the $C_{8}$ compounds may result in complex sources other than merely $C_{8}$ pollution. Moreover, the legacy precursors exhibited different particle affinities and experienced different degradation pathways, which may be the reasons for weak interrelationships (Ellis et al., 2004; Sun et al., 2015; Z. Wang et al., 2014).

Additionally, Wallington et al. (2006) calculated a 8:2 FTOH concentration of around $4 \times 10^{5}$ molecule $/ \mathrm{m}^{3}$ at $50 \mathrm{~m}$ above the sea level in July, which corresponded to a concentration of about $308 \mathrm{pg} / \mathrm{m}^{3}$, in the air of Bohai and Yellow Sea by modeling. The concentrations were in the range of the monitoring data in this study. The 8:2 FTOH annual emission in the model was estimated to be 1000 tons and its global distribution was assumed to be equal to propane from industrial sources. The consistency of modeling and monitoring data suggested the similar emission volume in 2012.

The gas phase dry deposition velocity was simulated from 0.0007 to $0.014 \mathrm{~m} / \mathrm{s}$ (mean: $0.0062 \pm 0.0036 \mathrm{~m} / \mathrm{s}$ ). The details of model results are presented in Table S9. The deposition velocity for each sample was the average value of the start and end velocities. A15, which was sampled around the Yellow Sea estuary, exhibited the fastest deposition velocity $(0.011 \mathrm{~m} / \mathrm{s})$. The deposition flux was estimated by multiplying the concentration with the corresponding deposition velocity. The dry deposition fluxes of $8: 2 \mathrm{FTOH}\left(0.27\right.$ to $\left.1.8 \mathrm{pg} / \mathrm{m}^{2} / \mathrm{s}\right)$ was higher than the other congeners, and samples A1 and A6 exhibited the largest deposition fluxes, all of which were occurred in the South Yellow Sea. A6 had the largest deposition flux of the YPFASs $\left(2.3 \mathrm{pg} / \mathrm{m}^{2} / \mathrm{s}\right)$ in the Yellow Sea, and A13 exhibited the largest deposition flux $\left(1.3 \mathrm{pg} / \mathrm{m}^{2} / \mathrm{s}\right)$ in the Bohai Sea.

\subsection{Distribution and transportation of ionic PFASs in surface water}

The spatial distributions of the $\sum$ PFASs in the surface water are presented in Fig. 2. PFOA, which exhibited a similar distribution pattern, was discussed together with the $\sum$ PFASs (Fig. S3). Relatively high concentrations of $\sum$ PFASs/PFOA (37-118 ng/L for $\sum$ PFASs and 33$106 \mathrm{ng} / \mathrm{L}$ for PFOA) were distributed at the mouth of the Laizhou Bay (W63-67, transect LZ), in the southern part of the Bohai Sea. The western part (W63 and W64, 52-60 ng/L) of the Laizhou Bay mouth exhibited lower $\sum$ PFAS concentrations than the eastern part (W65-66, 108$118 \mathrm{ng} / \mathrm{L}$ ). The western part is mainly influenced by the Yellow River, which recently suffered from decreasing water discharge and serious pollution (Gao et al., 2008; He et al., 2006). The eastern part is the gateway through which coastal water and adjacent river water move out of the Laizhou Bay. In the Laizhou Bay, rivers were the major contributor of PFAS pollution (P. Wang et al., 2014; Heydebreck et al., 2015).

In the Bohai Bay, $\sum$ PFAS concentrations increased from the north (9.4 ng/L at W57) to the south (23.5 ng/L at W55), thereby exhibiting an inverse trend with salinity (31.2 practical salinity units (PSU) at W57 and 30.5 PSU at W55). S. Wang et al. (2015) observed similar 


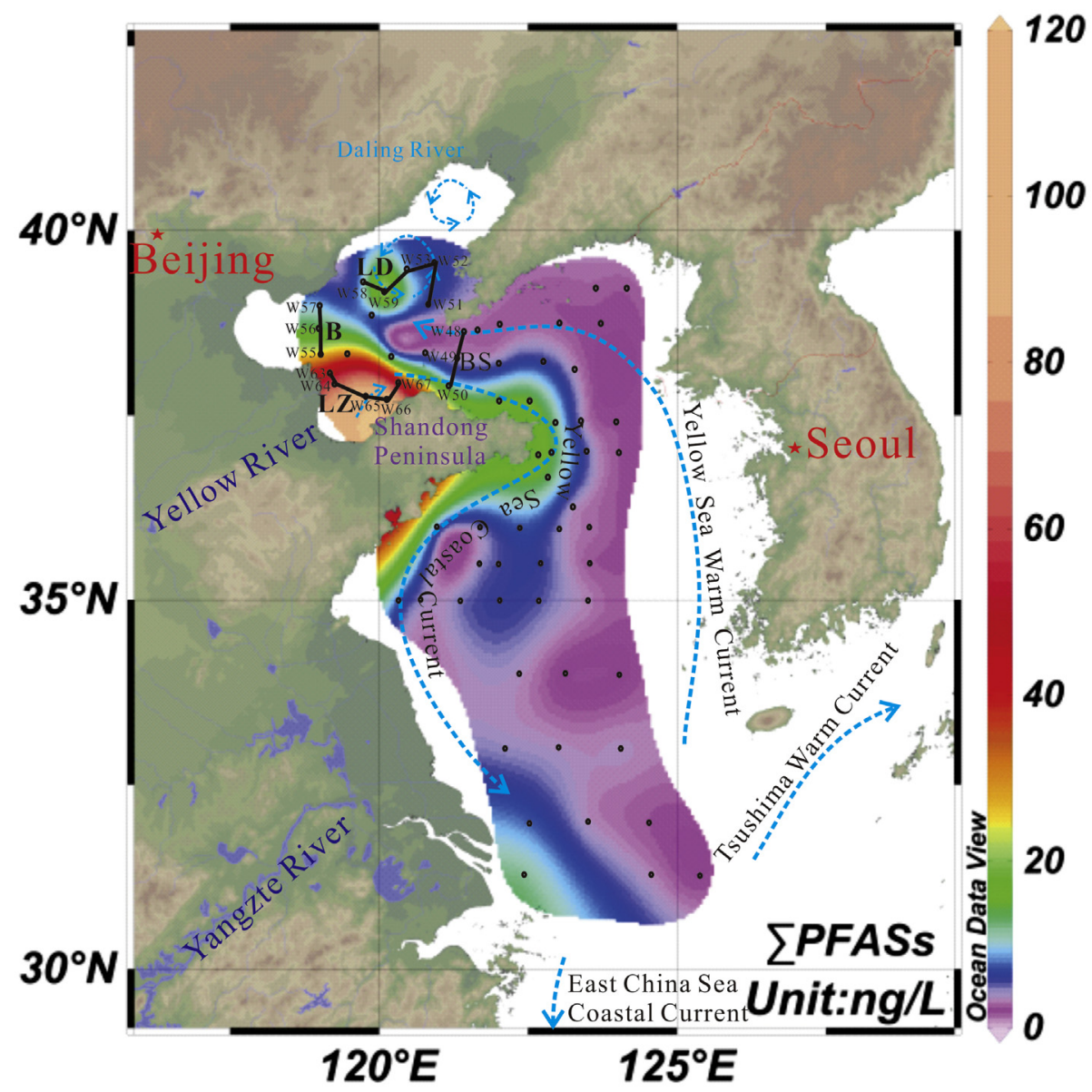

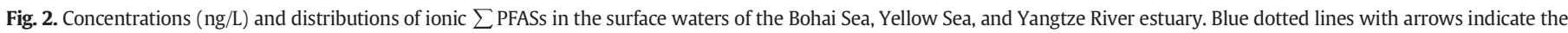

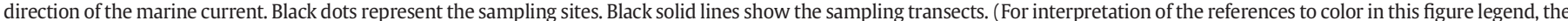
reader is referred to the web version of this article.)

trends in 2011-2013, and the freshwater input was considered as the major source. For the Liaodong Bay transect (W51, W52, W53, W58, and W59, transect LD), comparable $\sum$ PFAS concentrations around $6 \mathrm{ng} / \mathrm{L}$ were detected, except for site W59 (29 ng/L). It took at least three years for the PFASs to reach half their original concentrations in Liaodong Bay by coastal circulation (Wei et al., 2002).

Bohai Strait is the gateway for water exchange between the Bohai Sea and the Yellow Sea, given that it enters into the Bohai Sea through the southern strait and moves out from the Bohai Sea through the northern strait. For the Bohai Strait sampling transect (W48-50, transect BS), an increasing trend of $\sum$ PFAS concentrations was found from the north to the south (from 3.06 to $10.5 \mathrm{ng} / \mathrm{L}$ ), which indicates the input of PFASs from the Bohai Sea to the Yellow Sea.

In the Bohai Sea (covering $77300 \mathrm{~km}^{2}$ ), riverine input might be the major contributor of PFASs in coastal waters. In 2007, 2008, and 2011, Wang et al. (2012) and P. Wang et al. (2014) investigated 22 main rivers that deliver water into the Bohai Sea. The calculated input masses of PFOA was $4160 \mathrm{~kg} / \mathrm{a}$. 8:2 FTOH was one precursor of PFOA which was recognized as an indirect source. Assuming the yield of PFOA from 8:2 FTOH was about $1.5 \%$ (Ellis et al., 2004), the indirect source contributed about $1.28 \pm 0.58 \mathrm{pg} / \mathrm{m}^{3}$ of PFOA. Considered the mean deposition velocity of $0.0091 \pm 0.0015 \mathrm{~m} / \mathrm{s}$, the volume of PFOA from 8:2 FTOH degradation was estimated to be $28.4 \pm 2.12 \mathrm{~kg} / \mathrm{a}$, which was significantly lower than the riverine input. Unfortunately, the particle phase was not analyzed in this study. The indirect volume only represented the gas phase. In the future, simultaneously studies of gas and particle phase should be conducted to comprehensively understand the behaviors of PFASs in the coastal air and water.
In the Chinese Yellow Sea, higher $\sum$ PFAS concentrations were observed near the coast than in the open waters. No point sources of PFASs were discovered along the Yellow Sea coast. Ju et al. (2008) and Chen et al. (2012) investigated PFOA and PFOS along the Dalian coast. Concentrations of PFOA (0.17 to $95.7 \mathrm{ng} / \mathrm{L}$ ) were significantly higher than those of PFOS ( $<0.10$ to $2.3 \mathrm{ng} / \mathrm{L}$ ). On the eastern coast of the Yellow Sea, $\sum$ PFASs of around $10 \mathrm{ng} / \mathrm{L}$ suggested normal levels for the Korean coast (Naile et al., 2010). The marine current in the Yellow Sea was weak and the Lagrangian residual current was mostly wind-driven. The Yellow Sea coastal current transports water from the north to the south, which was conducive for the PFASs from the Shandong Peninsula to dilute and disperse. The warm Yellow Sea current delivers water from the south to the north and PFASs from the western South Korean coast could be carried into the Bohai Sea.

The distribution of PFBA in the Bohai Sea and Yellow Sea was similar to PFOA and other PFCAs (Fig. 3). For PFSAs, the Yangtze River estuary was the major source. Pan (2010) reported PFOS concentrations of up to $703.3 \mathrm{ng} / \mathrm{L}$ for the Yangtze River Delta. S.W. Xie et al. (2013) and T. Wang et al. (2015) investigated the industrial and domestic emissions of PFOS in China in 2010. The emission density around the Yangtze River Delta was higher than that of the Bohai Sea and Yellow Sea coasts. Moreover, the provinces that the Yangtze River runs through, such as Hubei and Jiangxi, exhibited higher emission volumes than other central areas of China, which elevated the PFOS concentrations for the Yangtze River estuary. FOSA presented a unique distribution pattern (Fig. 3). The coasts of Qingdao City, China and South Korea were the major sources of FOSA in the Yellow Sea water. FOSA is the product of neutral PFASs and one precursor of PFOS. The occurrence of FOSA in this surface water 

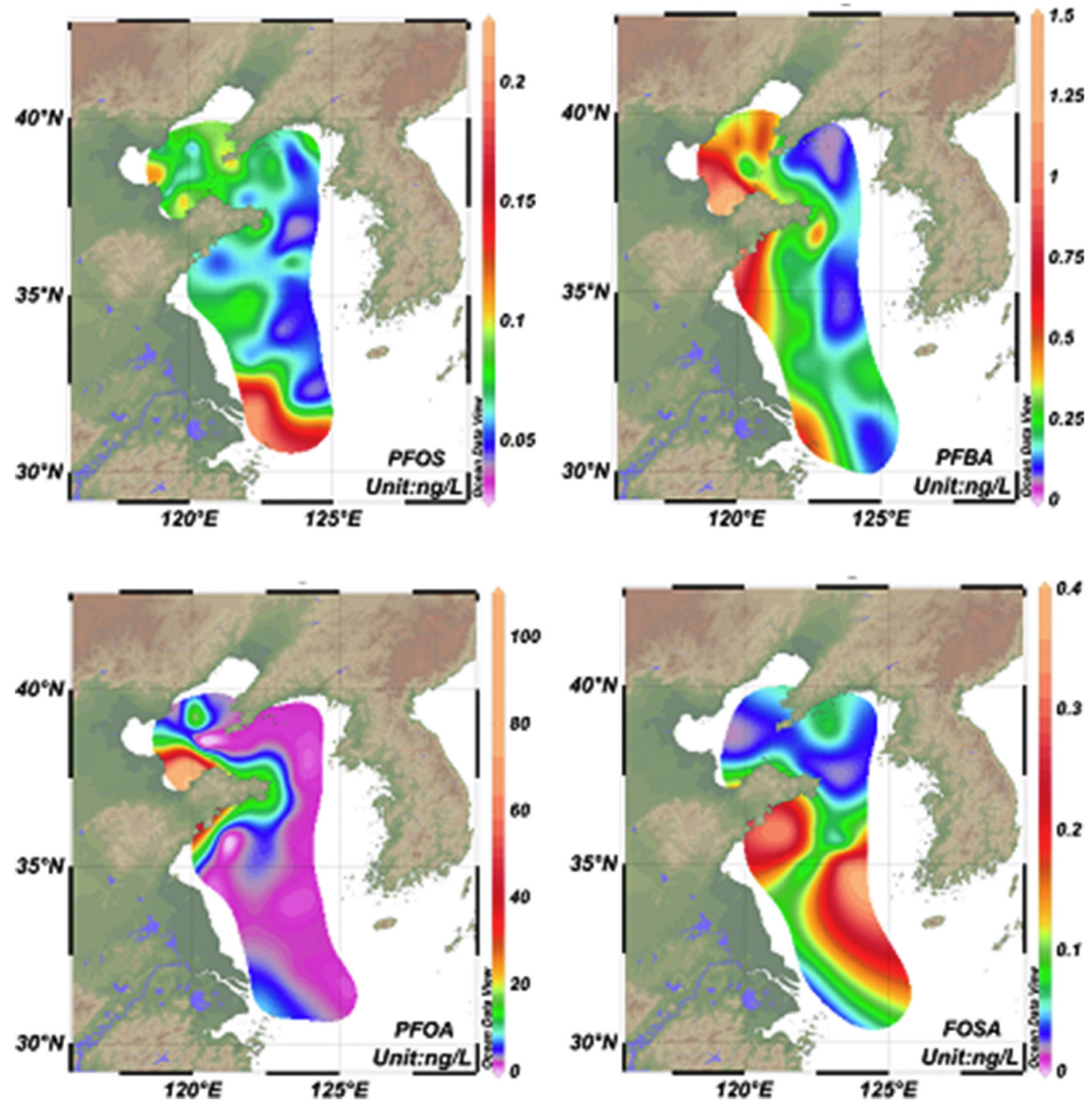

Fig. 3. Concentrations (ng/L) and distributions of PFOS, PFBA, PFOA, and FOSA in the surface waters of the Bohai Sea, Yellow Sea, and Yangtze River estuary.

suggested the degradation of ionic PFASs precursors in the Bohai and Yellow Seas.

\subsection{Comparison of PFAS concentrations in gaseous and dissolved phases}

The neutral PFASs comparison is presented in Table S10. Comparing with other coastal regions worldwide, $\sum$ FTOHs and 8:2 FTOH concentrations in the air above the Bohai and Yellow Seas were significantly higher than those of the air above the South China Sea (17.8 to $106 \mathrm{pg} / \mathrm{m}^{3}$, and12.5 to $75.5 \mathrm{pg} / \mathrm{m}^{3}$, respectively) (Lai et al., 2016), German coast ( 7.3 to $146 \mathrm{pg} / \mathrm{m}^{3}$, and 4.5 to $85 \mathrm{pg} / \mathrm{m}^{3}$, respectively) (Z. Wang et al., 2014), Japanese coast ( $<0.4$ to $5.0 \mathrm{pg} / \mathrm{m}^{3}$ ) (Piekarz et al., 2007), and east coast of the USA (5.46 to $156 \mathrm{pg} / \mathrm{m}^{3}$, and 1.65 to $91.3 \mathrm{pg} / \mathrm{m}^{3}$, respectively) (Shoeib et al., 2010). Concentrations of $\mathrm{MeFBSA} / \mathrm{E}$ in the air were higher than those in the air above the North Atlantic Ocean ( 0.11 to $0.44 \mathrm{pg} / \mathrm{m}^{3}$, and 0.09 to $0.57 \mathrm{pg} / \mathrm{m}^{3}$, respectively) (Z. Wang et al., 2015), but lower than those in the North Sea coastal air ( 0.1 to $3.9 \mathrm{pg} / \mathrm{m}^{3}$, and nd to $4.6 \mathrm{pg} / \mathrm{m}^{3}$, respectively) (Z. Xie et al., 2013), and western Antarctic Peninsula coastal air $\left(0.4\right.$ to $5.4 \mathrm{pg} / \mathrm{m}^{3}$, and 0.2 to $14.1 \mathrm{pg} / \mathrm{m}^{3}$, respectively) (Del Vento et al., 2012). As for FASA/Es, concentrations in air from the Bohai and Yellow Seas were comparable to those reported at Büsum on the German coast ( 0.4 to $13 \mathrm{pg} / \mathrm{m}^{3}$, and 0.5 to $3.6 \mathrm{pg} / \mathrm{m}^{3}$, respectively) for samples collected in 2011-2012
(Z. Wang et al., 2014). In most of the northern hemisphere, including the Arctic region (Ahrens et al., 2011), North Atlantic Ocean coast of Europe (Jahnke et al., 2007), Japan Sea to the Arctic Ocean (Cai et al., 2012a), and east coast of the USA (Shoeib et al., 2010), higher FASE concentrations were observed as compared to those in the air of the Bohai and Yellow Seas. Conversely, the FASA concentrations exhibited an inverse pattern.

Table S11 presents the PFOA and PFOS concentrations in the coastal and marine surface waters of China. The concentrations of PFOA (2.3 to $106 \mathrm{ng} / \mathrm{L}$ ) in the Bohai Sea water in the current study were comparable to those for the Dalian Coast (1.5 to $95.7 \mathrm{ng} / \mathrm{L}$ ) (Chen et al., 2012). For the Yellow Sea ( 0.89 to $14 \mathrm{ng} / \mathrm{L}$ ) and Yangtze River estuary, the PFOA concentrations ( 0.98 to $6.9 \mathrm{ng} / \mathrm{L}$ ) were comparable to those for the coastal areas of Hong Kong ( 0.67 to $5.5 \mathrm{ng} / \mathrm{L}$ ), though these were higher than those for the eastern and southern Chinese coasts (0.04 to $1.5 \mathrm{ng} / \mathrm{L}$ ) (Cai et al., 2012b) and the South China Sea (0.16 to $0.42 \mathrm{ng} / \mathrm{L}$ ) (Yamashita et al., 2005). As compared to other coastal areas globally, the PFOA concentrations in the Bohai Sea water were similar to those of the Tokyo Bay water ( 2.7 to $63 \mathrm{ng} / \mathrm{L}$ ), which is a semiclosed bay in Japan (Sakurai et al., 2010). The PFOA concentrations in the waters of the Yellow Sea and Yangtze River estuary were similar to those in the Baltic Sea (0.25 to $4.45 \mathrm{ng} / \mathrm{L}$ ) (Ahrens et al., 2010), but higher than those in the waters of the North Sea $(<0.2$ to $2.43 \mathrm{ng} / \mathrm{L})$ and coastal 
Norway (0.07 to $0.35 \mathrm{ng} / \mathrm{L}$ ) (Ahrens et al., 2010). The PFOS concentrations in the waters of the Bohai Sea $(<0.03$ to $0.12 \mathrm{ng} / \mathrm{L})$, Yellow Sea $(<0.03$ to $0.11 \mathrm{ng} / \mathrm{L})$, and Yangtze River estuary $(<0.03$ to $0.20 \mathrm{ng} / \mathrm{L})$ were comparable to those of the Dalian coast, China $(0.1$ to $0.2 \mathrm{ng} / \mathrm{L})$ (Chen et al., 2012), eastern to southern Chinese coasts (0.02 to $0.07 \mathrm{ng} / \mathrm{L}$ ) (Cai et al., 2012b), and the South China Sea (0.008 to $0.11 \mathrm{ng} / \mathrm{L}$ ) (Yamashita et al., 2005). Kwok et al. (2015) investigated the PFOA and PFOS levels in the South China Sea for the same year (2012) as the current study. Concentrations of PFOA in the South China Sea in 2012 were significantly lower than those in the Bohai Sea, Yellow Sea, and Yangtze River estuary. In contrast, the PFOS concentrations in the South China Sea were higher than those of the presently studied seas. Additionally, the PFOS concentrations were higher than the PFOA concentrations in the South China Sea, and the same compositional pattern was observed in the surface river waters from the Pearl River or the Pearl River estuary (Liu et al., 2015; Pan et al., 2014; So et al., 2007; Zhang et al., 2013). However, an inverse pattern was observed in the Bohai Sea, Yellow Sea, and Yangtze River estuary, as well as most other rivers studied in China (Chen et al., 2017; Sun et al., 2017; P. Wang et al., 2014; Wang et al., 2012). This may be due to the evaluation of PFOA and PFOS in Chinese surface waters conducted mainly after 2002, the year when the production of PFOS and related compounds in North American and European countries dramatically decreased due to the execution of the voluntary phase-out. Although the manufacturing of PFOS in China increased from 2002, the volume was much lower than it was globally before 2002 (MEP, 2008). Moreover, the introduction of a shorter-chained substitute resulted in higher PFBS concentrations than for PFOS in industrial parks (Chen et al., 2015; Jin et al., 2015) and inland lakes (for instance, the Tangxun Lake). As compared to PFOS, the voluntary phase-out of PFOA was executed much later (2015), and until recently, no global legislation had been proposed. Only one study collected river samples from the Hun River in Liaoning Province in 2002, exhibited significantly higher PFOS concentrations (0.2 to $44.6 \mathrm{ng} / \mathrm{L}$ ) as compared to PFOA (<0.1 to $1.6 \mathrm{ng} / \mathrm{L}$ ) (Jin et al., 2009).

\section{Conclusion}

Concentrations of the neutral PFASs in the gas phase were consistent with those reported in the urban and rural regions of China. Air masses with higher concentrations were mainly transported from the coast of the Yellow Sea, including the Chinese and South Korean sides, whereas air masses with lower concentrations were mainly passed through the Yellow Sea and Japan Sea, northeastern China, Mongolia, and Russia. PFOA was the predominant ionic congener and accounted for 51\%$90 \%$ of the ionic $\sum$ PFASs in surface water. The spatial distribution indicated that the major source of PFCAs was located around the Laizhou Bay, whereas for the PFSAs, the Yangtze River estuary exhibited higher concentrations than the other areas. The semiclosed geographical conditions influenced the dispersion, dilution, and exchange of PFASs in the Bohai Sea. Direct releases from the industrial and domestic activities were the main sources, whereas contribution from the degradation of neutral PFASs was minimal.

\section{Acknowledgement}

This study was supported by the Natural Science Foundation of China (NSFC 41603101) and Chinese Academy of Sciences (13337 KYSB20130013, 2013T2Z0032, KZZD-EW-14, and XDA11020401). We are grateful for the field assistance from the crew of Research Vessel Dongfanghong 2 of the Ocean University of China.

\section{Appendix A. Supplementary data}

Supplementary data to this article can be found online at http://dx. doi.org/10.1016/j.scitotenv.2017.04.147.

\section{References}

Ahrens, L., 2011. Polyfluoroalkyl compounds in the aquatic environment: a review of their occurrence and fate. J. Environ. Monit. 13, 20-31.

Ahrens, L., Barber, J.L., Xie, Z., Ebinghaus, R., 2009. Longitudinal and latitudinal distribution of perfluoroalkyl compounds in the surface water of the Atlantic Ocean. Environ. Sci. Technol. 43, 3122-3127.

Ahrens, L., Gerwinski, W., Theobald, N., Ebinghaus, R., 2010. Sources of polyfluoroalky compounds in the North Sea, Baltic Sea and Norwegian Sea: evidence from their spatial distribution in surface water. Mar. Pollut. Bull. 60, 255-260.

Ahrens, L., Shoeib, M., Del Vento, S., Codling, G., Halsall, C., 2011. Polyfluoroalkyl compounds in the Canadian Arctic atmosphere. Environ. Chem. 8, 399-406.

Armitage, J.M., MacLeod, M., Cousins, I.T., 2009. Modeling the global fate and transport of perfluorooctanoic acid (PFOA) and perfluorooctanoate (PFO) emitted from direct sources using a multispecies mass balance model. Environ. Sci. Technol. 43, 1134-1140.

Bao, J., Liu, W., Liu, L., Jin, Y., Dai, J., Ran, X., Zhang, Z., Tsuda, S., 2010. Perfluorinated compounds in the environment and the blood of residents living near fluorochemical plants in Fuxin, China. Environ. Sci. Technol. 45, 8075-8080.

Butt, C.M., Young, C.J., Mabury, S.A., Hurley, M.D., Wallington, T.J., 2009. Atmospheric chemistry of $4: 2$ fluorotelomer acrylate $\mathrm{C} 4 \mathrm{~F} 9 \mathrm{CH} 2 \mathrm{CH} 2 \mathrm{OC}(\mathrm{O}) \mathrm{CH}=\mathrm{CH} 2$ : kinetics, mechanisms, and products of chlorine-atom- and OH-radical-initiated oxxidation. J. Phys. Chem. A 113, 3155-3161.

Butt, C.M., Berger, U., Bossi, R., Tomy, G.T., 2010. Levels and trends of poly- and perfluorinated compounds in the arctic environment. Sci. Total Environ. 408, 2936-2965

Cai, M., Xie, Z., Moeller, A., Yin, Z., Huang, P., Cai, M., Yang, H., Sturm, R., He, J., Ebinghaus, R., 2012a. Polyfluorinated compounds in the atmosphere along a cruise pathway from the Japan Sea to the Arctic Ocean. Chemosphere 87, 989-997.

Cai, M., Zhao, Z., Yang, H., Yin, Z., Hong, Q., Sturm, R., Ebinghaus, R., Ahrens, L., Cai, M., He, J., Xie, Z., 2012b. Spatial distribution of per- and polyfluoroalkyl compounds in coastal waters from the East to South China Sea. Environ. Pollut. 161, 162-169.

Cai, M., Zhao, Z., Yin, Z., Ahrens, L., Huang, P., Cai, M., Yang, H., He, J., Sturm, R., Ebinghaus, R., Xie, Z., 2012c. Occurrence of perfluoroalkyl compounds in surface waters from the North Pacific to the Arctic Ocean. Environ. Sci. Technol. 46, 661-668.

Chen, H., Zhang, C., Han, J., Yu, Y., Zhang, P., 2012. PFOS and PFOA in influents, effluents, and biosolids of Chinese wastewater treatment plants and effluent-receiving marine environments. Environ. Pollut. 170, 26-31.

Chen, H., Zhang, C., Han, J.B., Sun, R.J., Kong, X.Y., Wang, X.M., He, X., 2015. Levels and spatial distribution of perfluoroalkyl substances in China Liaodong Bay basin with concentrated fluorine industry parks. Mar. Pollut. Bull. 101, 965-971.

Chen, H., Wang, X., Zhang, C., Sun, R., Han, J., Han, G., Yang, W., He, X., 2017. Occurrence and inputs of perfluoroalkyl substances (PFASs) from rivers and drain outlets to the Bohai Sea, China. Environ. Pollut. 221, 234-243.

Del Vento, S., Halsall, C. Gioia, R., Jones, K., Dachs, J., 2012. Volatile per- and polyfluoroalkyl compounds in the remote atmosphere of the western Antarctic Peninsula: an indirect source of perfluoroalkyl acids to Antarctic waters? Atmos. Pollut Res. 3, 450-455.

D'Eon, J.C., Hurley, M.D., Wallington, T.J., Mabury, S.A., 2006. Atmospheric chemistry of $\mathrm{N}$-methyl perfluorobutane sulfonamidoethanol, $\mathrm{C}_{4} \mathrm{~F}_{9} \mathrm{SO}_{2} \mathrm{~N}\left(\mathrm{CH}_{3}\right) \mathrm{CH}_{2} \mathrm{CH}_{2} \mathrm{OH}$ : kinetics and mechanism of reaction with $\mathrm{OH}$. Environ. Sci. Technol. 40 $1862-1868$.

Dreyer, A., Matthias, V., Temme, C., Ebinghaus, R., 2009. Annual time series of air concentrations of polyfluorinated compounds. Environ. Sci. Technol. 43, 4029-4036.

Ellis, D.A., Martin, J.W., De Silva, A.O., Mabury, S.A., Hurley, M.D., Sulbaek Andersen, M.P. Wallington, T.J., 2004. Degradation of fluorotelomer alcohols: a likely atmospheric source of perfluorinated carboxylic acids. Environ. Sci. Technol. 38, 3316-3321.

Gao, Y., Fu, J., Zeng, L., Li, A., Li, H., Zhu, N., Liu, R., Liu, A., Wang, Y., Jiang, G., 2014. Occurrence and fate of perfluoroalkyl substances in marine sediments from the Chinese Bohai Sea, Yellow Sea, and East China Sea. Environ. Pollut. 194, 60-68.

Gao, J., Liu, L., Liu, X., Lu, J., Zhou, H., Huang, S., Wang, Z., Spear, P.A., 2008. Occurrence and distribution of organochlorine pesticides - lindane, p, $\mathrm{p}^{\prime}$-DDT, and heptachlor epoxide - in surface water of China. Environ. Int. 34, 1097-1103.

He, M.-C., Sun, Y., Li, X.-R., Yang, Z.-F., 2006. Distribution patterns of nitrobenzenes and polychlorinated biphenyls in water, suspended particulate matter and sediment from mid- and down-stream of the Yellow River (China). Chemosphere 65, 365-374.

Heydebreck, F., Tang, J., Xie, Z., Ebinghaus, R., 2015. Alternative and legacy perfluoroalky substances: differences between European and Chinese river/estuary systems. Environ. Sci. Technol. 49, 8386-8395.

Houde, M., De Silva, A.O., Muir, D.C.G., Letcher, R.J., 2011. Monitoring of perfluorinated compounds in aquatic biota: an updated review. Environ. Sci. Technol. 45 7962-7973

Jahnke, A., Berger, U., Ebinghaus, R., Temme, C., 2007. Latitudinal gradient of airborne polyfluorinated alkyl substances in the marine atmosphere between Germany and South Africa (53 degrees N-33 degrees S). Environ. Sci. Technol. 41, 3055-3061.

Jin, Y.H., Liu, W., Sato, I., Nakayama, S.F., Sasaki, K., Saito, N., Tsuda, S., 2009. PFOS and PFOA in environmental and tap water in China. Chemosphere 77, 605-611.

Jin, H.B., Zhang, Y.F., Zhu, L.Y., Martin, J.W., 2015. Isomer profiles of perfluoroalkyl substances in water and soil surrounding a Chinese fluorochemical manufacturing park. Environ. Sci. Technol. 49, 4946-4954.

Ju, X., Jin, Y., Sasaki, K., Saito, N., 2008. Perfluorinated surfactants in surface, subsurface water and microlayer from Dalian Coastal waters in China. Environ. Sci. Technol. 42, 3538-3542.

Kim, S.-K., 2012. Watershed-based riverine discharge loads and emission factor of perfluorinated surfactants in Korean peninsula. Chemosphere 89, 995-1002. 
Kim, S.K., Shoeib, M., Kim, K.S., Park, J.E., 2012. Indoor and outdoor poly- and perfluoroalkyl substances (PFASs) in Korea determined by passive air sampler. Environ. Pollut. 162, 144-150.

Kissa, E., 2001. In: Dekker, M. (Ed.), Fluorinated Surfactants and Repellents. Marcel Dekker, New York.

Kwok, K.Y., Wang, X.H., Ya, M.L., Li, Y.Y., Zhang, X.H., Yamashita, N., Lam, J.C.W., Lam, P.K.S. 2015. Occurrence and distribution of conventional and new classes of per- and polyfluoroalkyl substances (PFASs) in the South China Sea. J. Hazard. Mater. 285, 389-397.

Labadie, P., Chevreuil, M., 2011. Biogeochemical dynamics of perfluorinated alkyl acids and sulfonates in the River Seine (Paris, France) under contrasting hydrological conditions. Environ. Pollut. 159, 3634-3639.

Lai, S.C., Song, J.W., Song, T.L., Huang, Z.J., Zhang, Y.Y., Zhao, Y., Liu, G.C., Zheng, J.Y., Mi, W.Y., Tang, J.H., Zou, S.C., Ebinghaus, R., Xie, Z.Y., 2016. Neutral polyfluoroalkyl substances in the atmosphere over the northern South China Sea. Environ. Pollut. 214, 449-455.

Li, J., Del Vento, S., Schuster, J., Zhang, G., Chakraborty, P., Kobara, Y., Jones, K.C., 2011 Perfluorinated compounds in the Asian atmosphere. Environ. Sci. Technol. 45, $7241-7248$.

Lim, T.C., Wang, B., Huang, J., Deng, S., Yu, G., 2011. Emission inventory for PFOS in China: review of past methodologies and suggestions. TheScientificWorldJOURNAL 11 1963-1980.

Lindstrom, A.B., Strynar, M.J., Libelo, E.L., 2011. Polyfluorinated compounds: past, present and future. Environ. Sci. Technol. 45, 7954-7961.

Liu, B., Zhang, H., Xie, L., Li, J., Wang, X., Zhao, L., Wang, Y., Yang, B., 2015. Spatial distribution and partition of perfluoroalkyl acids (PFAAs) in rivers of the Pearl River Delta, southern China. Sci. Total Environ. 524, 1-7.

Ma, J.M., Daggupaty, S.M., 2000. Effective dry deposition velocities for gases and particles over heterogeneous terrain. J. Appl. Meteorol. 39, 1379-1390.

Ma, J.M., Daggupaty, S., Harner, T., Li, Y.F., 2003. Impacts of lindane usage in the Canadian prairies on the Great Lakes ecosystem. 1. Coupled atmospheric transport model and modeled concentrations in air and soil. Environ. Sci. Technol. 37, 3774-3781.

MEP, C., 2008. In: China, M.o.E.P.o. (Ed.), Preliminary Information on Risk Management Evaluation of PFOS's in China.

Möller, A., Ahrens, L., Surm, R., Westerveld, J., van der Wielen, F., Ebinghaus, R., de Voogt P., 2010. Distribution and sources of polyfluoroalkyl substances (PFAS) in the River Rhine watershed. Environ. Pollut. 158, 3243-3250.

Müller, C.E., Spiess, N., Gerecke, A.C., Scheringer, M., Hungerbühler, K., 2011. Quantifying diffuse and point inputs of perfluoroalkyl acids in a nonindustrial river catchment. Environ. Sci. Technol. 45, 9901-9909.

Naile, J.E., Khim, J.S., Wang, T., Chen, C., Luo, W., Kwon, B.-O., Park, J., Koh, C.-H., Jones, P.D., Lu, Y., Giesy, J.P., 2010. Perfluorinated compounds in water, sediment, soil and biota from estuarine and coastal areas of Korea. Environ. Pollut. 158, 1237-1244.

Nguyen, T.V., Reinhard, M., Gin, K.Y.-H., 2013. Rate laws and kinetic modeling of $N$-ethyl perfluorooctane sulfonamidoethanol (N-EtFOSE) transformation by hydroxyl radical in aqueous solution. Water Res. 47, 2241-2250.

OECD, 2002. Hazard Assessment of Perfluorooctane Sulfonate (PFOS) and Its Salts.

Pan, C.G., Ying, G.G., Liu, Y.S., Zhang, Q.Q., Chen, Z.F., Peng, F.J., Huang, G.Y., 2014. Contamination profiles of perfluoroalkyl substances in five typical rivers of the Pearl River Delta region, South China. Chemosphere 114, 16-25.

Pan, G., You, C., 2010. Sediment-water distribution of perfluorooctane sulfonate (PFOS) in Yangtze River Estuary. Environ. Pollut. 158, 1363-1367.

Piekarz, A.M., Primbs, T., Field, J.A., Barofsky, D.F., Simonich, S., 2007. Semivolatile fluorinated organic compounds in Asian and Western U.S. air masses. Environ. Sci. Technol. $41,8248-8255$

Plumlee, M.H., McNeill, K., Reinhard, M., 2009. Indirect photolysis of perfluorochemicals hydroxyl radical-initiated oxidation of $\mathrm{N}$-ethyl perfluorooctane sulfonamido acetate (N-EtFOSAA) and other perfluoroalkanesulfonamides. Environ. Sci. Technol. 43, 3662-3668.

Sakurai, T., Serizawa, S., Isobe, T., Kobayashi, J., Kodama, K., Kume, G., Lee, J.H., Maki, H. Imaizumi, Y., Suzuki, N., Horiguchi, T., Morita, M., Shiraishi, H., 2010. Spatial, phase, and temporal distributions of perfluorooctane sulfonate (PFOS) and perfluorooctanoate (PFOA) in Tokyo Bay, Japan. Environ. Sci. Technol. 44, 4110-4115

Schenker, U, Scheringer, M., Macleod, M., Martin, J.W., Cousins, I.T., Hungerbuhler, K, 2008. Contribution of volatile precursor substances to the flux of perfluorooctanoate to the arctic. Environ. Sci. Technol. 42, 3710-3716.

Shoeib, M., Vlahos, P., Harner, T., Peters, A., Graustein, M., Narayan, J., 2010. Survey of polyfluorinated chemicals (PFCs) in the atmosphere over the northeast Atlantic Ocean. Atmos. Environ. 44, 2887-2893.
So, M.K., Taniyasu, S., Yamashita, N., Giesy, J.P., Zheng, J., Fang, Z., Im, S.H., Lam, P.K.S., 2004. Perfluorinated compounds in coastal waters of Hong Kong, South China, and Korea. Environ. Sci. Technol. 38, 4056-4063.

So, M.K., Miyake, Y., Yeung, W.Y., Ho, Y.M., Taniyasu, S., Rostkowski, P., Yamashita, N., Zhou, B.S., Shi, X.J., Wang, J.X., Giesy, J.P., Yu, H., Lam, P.K.S., 2007. Perfluorinated compounds in the Pearl River and Yangtze River of China. Chemosphere 68, 2085-2095.

Sun, H., Li, F., Zhang, T., Zhang, X., He, N., Song, Q., Zhao, L., Sun, L., Sun, T., 2011. Perfluorinated compounds in surface waters and WWTPs in Shenyang, China: mass flows and source analysis. Water Res. 45, 4483-4490.

Sun, Y., Zhang, Q., Wang, H., Wang, W., 2015. OH radical-initiated oxidation degradation and atmospheric lifetime of $\mathrm{N}$-ethylperfluorobutyramide in the presence of $\mathrm{O} 2$ / NOx. Chemosphere 134, 241-249.

Sun, Z., Zhang, C., Yan, H., Han, C., Chen, L., Meng, X., Zhou, Q., 2017. Spatiotemporal distribution and potential sources of perfluoroalkyl acids in Huangpu River, Shanghai, China. Chemosphere 174, 127-135.

UNEP, 2009. The Conference of the Parties 4 of the Stockholm Convention (COP-4) in Geneva Placed Perfluorooctane Sulfonate and Perfluorooctane Sulfonyl Fluoride (PFOS and PFOSF) (in Annex B).

USEPA, 2006. 2010/2015 PFOA Stewardship Program.

Wallington, T.J., Hurley, M.D., Xia, J., Wuebbles, D.J., Sillman, S., Ito, A., Penner, J.E., Ellis, D.A., Martin, J., Mabury, S.A., Nielsen, O.J., Andersen, M.P.S., 2006. Formation of $\mathrm{C7F} 15 \mathrm{COOH}$ (PFOA) and other perfluorocarboxylic acids during the atmospheric oxidation of $8: 2$ fluorotelomer alcohol. Environ. Sci. Technol. 40, 924-930.

Wang, T., Lu, Y., Chen, C., Naile, J.E., Khim, J.S., Park, J., Luo, W., Jiao, W., Hu, W., Giesy, J.P., 2011. Perfluorinated compounds in estuarine and coastal areas of north Bohai Sea, China. Mar. Pollut. Bull. 62, 1905-1914.

Wang, T., Khim, J.S., Chen, C., Naile, J.E., Lu, Y., Kannan, K., Park, J., Luo, W., Jiao, W., Hu, W., Giesy, J.P., 2012. Perfluorinated compounds in surface waters from Northern China: comparison to level of industrialization. Environ. Int. 42, 37-46.

Wang, P., Lu, Y., Wang, T., Fu, Y., Zhu, Z., Liu, S., Xie, S., Xiao, Y., Giesy, J.P., 2014. Occurrence and transport of 17 perfluoroalkyl acids in 12 coastal rivers in south Bohai coastal region of China with concentrated fluoropolymer facilities. Environ. Pollut. 190, $115-122$.

Wang, Z., Xie, Z., Moeller, A., Mi, W., Wolschke, H., Ebinghaus, R., 2014. Atmospheric concentrations and gas/particle partitioning of neutral poly- and perfluoroalkyl substances in northern German coast. Atmos. Environ. 95, 207-213.

Wang, S., Wang, H., Zhao, W., Cao, Y., Wan, Y., 2015. Investigation on the distribution and fate of perfluorooctane sulfonate (PFOS) and perfluorooctanoate (PFOA) in a sewageimpacted bay. Environ. Pollut. 205, 186-198.

Wang, T., Wang, P., Meng, J., Liu, S., Lu, Y., Khim, J.S., Giesy, J.P., 2015. A review of sources, multimedia distribution and health risks of perfluoroalkyl acids (PFAAs) in China. Chemosphere 129, 87-99.

Wang, Z., Xie, Z., Mi, W., Möller, A., Wolschke, H. Ebinghaus, R., 2015. Neutral poly/perfluoroalkyl substances in air from the Atlantic to the Southern Ocean and in Antarctic snow. Environ. Sci. Technol. 49, 7770-7775.

Washington, J.W., Naile, J.E., Jenkins, T.M., Lynch, D.G., 2014. Characterizing fluorotelomer and polyfluoroalkyl substances in New and aged fluorotelomer-based polymers for degradation studies with GC/MS and LC/MS/MS. Environ. Sci. Technol. 48, 5762-5769.

Wei, H., Tian, T., Zhou, F., Zhao, L., 2002. Numerical study on the water exchange of the Bohai Sea: simulation of the half-life time by dispersion model. J. Ocean Univ. Qingdao 519-525.

Xie, S.W., Lu, Y.L., Wang, T.Y., Liu, S.J., Jones, K., Sweetman, A., 2013. Estimation of PFOS emission from domestic sources in the eastern coastal region of China. Environ. Int. 59, 336-343.

Xie, Z., Zhao, Z., Moeller, A., Wolschke, H., Ahrens, L., Sturm, R., Ebinghaus, R., 2013. Neutral poly- and perfluoroalkyl substances in air and seawater of the North Sea. Environ. Sci. Pollut. Res. 20, 7988-8000.

Yamashita, N., Kannan, K., Taniyasu, S., Horii, Y., Petrick, G., Gamo, T., 2005. A global survey of perfluorinated acids in oceans. Mar. Pollut. Bull. 51, 658-668.

Zhang, Y., Lai, S., Zhao, Z., Liu, F., Chen, H., Zou, S., Xie, Z., Ebinghaus, R., 2013. Spatial distribution of perfluoroalkyl acids in the Pearl River of Southern China. Chemosphere 93, 1519-1525.

Zhou, Z., Liang, Y., Shi, Y., Xu, L., Cai, Y., 2013. Occurrence and transport of perfluoroalkyl acids (PFAAs), including short-chain PFAAs in Tangxun Lake, China. Environ. Sci. Technol. 47, 9249-9257. 